IJM

33,6

604

\title{
GUEST EDITORIAL Active ageing in Europe: the role of organisations
}

Kène Henkens

Netherlands Interdisciplinary Demographic Institute (NIDI), The Hague, The Netherlands and Department of Sociology, Tilburg University, Tilburg, The Netherlands, and

Joop Schippers

Faculty of Law, Economics and Governance, Utrecht University, Utrecht, The Netherlands

\begin{abstract}
Purpose - The purpose of this paper (overview) is to provide a brief introduction to the topic of active ageing and summarise the seven studies included in this special issue. The authors also acknowledge those who were instrumental in bringing this issue to fruition.

Design/methodology/approach - The International Journal of Manpower's usual double-blind review process was used to select the seven papers included in this special issue. The papers themselves all have a cross-national perspective using data from eight European countries. These papers represent a wide variety of designs, methodologies and analytic strategies used to study active ageing in the paid labour force as well as in civil society. The papers make use of large-scale surveys among employers and volunteers, case studies in organisations, and vital statistics.

Findings - The findings of the studies included in this special issue provide insights into the factors and mechanisms that hamper higher participation levels of older adults in paid employment and civil society, and give suggestions on how to improve their inclusion and how to deal with an ageing workforce.

Originality/value - Taken as a collective, the papers in this special issue help propel forward in significant ways the study of active ageing from an international and interdisciplinary perspective.

Keywords Europe, Labour, Changing society, Retirement, Active ageing, International perspective, Civil society, Employers' survey, Case studies

Paper type Viewpoint
\end{abstract}

\section{The ageing of the European population}

In the coming decades European labour markets will be facing an unprecedented challenge: after centuries of abundant population growth, as more European countries will enter a stage in which population growth is at the very minimum flattening, coming to a halt, or even turning towards decline (van Nimwegen and van der Erf, 2010). This is the result of what is known as the second demographic transition. This term is used by demographers to describe the phenomenon in which after a decrease in mortality rates, resulting in an ever-higher life expectancy, birth rates also decline, resulting in a new, lower equilibrium between birth and death rates. In several European countries birth rates have fallen so dramatically that they are not even high enough to replace the current population, with a declining population as a consequence. Because of the lower mortality rates people live longer on average. Combined with lower birth rates this implies an ageing of the population.

The process of an ageing population is not identical in all western countries. The major reason for this is the difference in the moment at which the decline in birth rates
International Journal of Manpower Vol. 33 No. 6, 2012 pp. $604-611$

(C) Emerald Group Publishing Limited 0143-7720

DOI $10.1108 / 01437721211261840$ 
has set in and the speed at which it proceeds. As Table I shows, Spain and Italy will be among the countries with the highest share of older people in 2050, while Sweden, Denmark and especially the Netherlands will have a relatively young population. But also for these relatively "young" countries the share of persons over 65 will have almost doubled during the first half of this century.

Major consequences for the welfare state and the labour market

These demographic developments will have major consequences for the welfare state. More people will depend on old-age pensions, and care for an increasing number of chronically ill seniors may result in higher health care costs. In the meantime, the share of people that may contribute to GDP by paying taxes and social security premiums is falling. In this context it does not come as a surprise that within the European population there is widespread concern that future pension levels will be insufficient (Hershey et al., 2010).

Already before the care sector is confronted with an increasing demand for care from growing numbers of $80+$ citizens, the labour market will have to face the challenges of the demographic changes described above (Klosse and Schippers, 2008). First, cohorts of men and women in the age categories from which employers usually recruit their workforce will constitute a smaller share of the whole population, as increasing numbers "outlive" the current working age. Second, within the labour force the emphasis will lie much more on older workers, as the inflow of young workers

\begin{tabular}{lccccccccc}
\hline & \multicolumn{8}{c}{ Percentage aged $0-14$} & \multicolumn{3}{c}{ Percentage aged 15-64 } & \multicolumn{3}{c}{ Percentage aged $65+$} \\
& 2004 & 2025 & 2050 & 2004 & 2025 & 2050 & 2004 & 2025 & 2050 \\
\hline & & & & & & & & & \\
EU25 & 16.4 & 14.4 & 13.4 & 67.2 & 63.0 & 56.7 & 16.4 & 22.6 & 29.9 \\
EU15 & 16.3 & 14.4 & 13.5 & 66.7 & 62.8 & 56.5 & 17.0 & 22.8 & 30.0 \\
New member states & 16.7 & 14.4 & 13.2 & 69.7 & 64.5 & 57.7 & 13.6 & 21.1 & 29.1 \\
Belgium & 17.3 & 15.6 & 14.7 & 65.6 & 61.9 & 57.6 & 17.1 & 22.5 & 27.7 \\
Czech Republic & 15.2 & 13.5 & 12.6 & 70.8 & 64.1 & 56.5 & 14.0 & 22.4 & 30.9 \\
Denmark & 18.9 & 15.9 & 15.7 & 66.2 & 62.9 & 60.2 & 14.9 & 21.2 & 24.1 \\
Germany & 14.7 & 12.9 & 11.9 & 67.3 & 62.5 & 56.5 & 18.0 & 24.6 & 31.6 \\
Greece & 14.5 & 13.3 & 12.3 & 67.7 & 63.9 & 55.2 & 17.8 & 22.8 & 32.5 \\
Spain & 14.5 & 12.8 & 11.5 & 68.6 & 65.2 & 52.9 & 16.9 & 22.0 & 35.6 \\
France & 18.6 & 16.7 & 15.8 & 65.1 & 60.9 & 57.0 & 16.3 & 22.4 & 27.2 \\
Ireland & 20.9 & 18.2 & 16.0 & 68.0 & 65.3 & 57.8 & 11.1 & 16.5 & 26.2 \\
Italy & 14.2 & 12.1 & 11.2 & 66.6 & 62.9 & 53.5 & 19.2 & 25.0 & 35.3 \\
Hungary & 15.9 & 14.3 & 13.8 & 68.6 & 63.7 & 58.1 & 15.5 & 22.0 & 28.1 \\
The Netherlands & 18.5 & 16.1 & 15.8 & 67.6 & 63.3 & 60.7 & 13.9 & 20.6 & 23.5 \\
Austria & 16.3 & 13.8 & 12.3 & 68.2 & 64.1 & 57.3 & 15.5 & 22.1 & 30.4 \\
Poland & 17.2 & 14.6 & 13.0 & 69.8 & 64.3 & 57.6 & 13.0 & 21.1 & 29.4 \\
Portugal & 15.7 & 14.2 & 13.1 & 67.4 & 63.7 & 55.0 & 16.9 & 22.1 & 31.9 \\
Slovenia & 14.6 & 13.4 & 12.8 & 70.4 & 63.8 & 56.0 & 15.0 & 22.8 & 31.2 \\
Slovakia & 17.6 & 14.0 & 12.8 & 70.9 & 67.1 & 57.9 & 11.5 & 18.9 & 29.3 \\
Finland & 17.6 & 16.0 & 15.3 & 66.8 & 59.4 & 57.8 & 15.6 & 24.6 & 26.9 \\
Sweden & 17.8 & 17.1 & 16.3 & 65.0 & 60.7 & 59.4 & 17.2 & 22.2 & 24.3 \\
UK & 18.3 & 16.1 & 14.7 & 65.7 & 63.0 & 58.7 & 16.0 & 20.9 & 26.6 \\
Bulgaria & 14.2 & 11.7 & 11.5 & 68.7 & 64.5 & 55.0 & 17.1 & 23.8 & 33.5 \\
Romania & 16.4 & 14.1 & 12.5 & 69.1 & 66.9 & 57.9 & 14.5 & 19.0 & 29.6 \\
& & & & & & & & &
\end{tabular}

Source: Eurostat (2005)

\section{Active ageing in Europe}

605

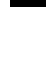


IJM

33,6

606 entering the labour market is stagnating[1]. This may have implications for organisations, which traditionally have been structured like a pyramid, with a small number of experienced, older managers at the top and broader layers of different categories of younger workers in lower echelons of the organisation (Ekamper, 1997). In such organisations, growing older used to go hand-in-hand with upward job mobility. However, as the share of the staff entering the category of older workers will increase over the next few decades, it will no longer be possible to guarantee upward job mobility for every older worker, or even for a majority. Many organisations will thus have to face the challenge of how to deal with the - perhaps frustrated expectations of older workers who over the years nurtured the idea of having a career within the company and making the most of their experience and their ambitions.

In those countries with an official, general retirement age of 65 (which is rather widespread in Europe), 2010 was the year when the first post-war babies reached the age of 65 . In coming years most members of the populous baby-boom generation will leave the labour market (insofar as they have not done so already), confronting organisations with the need to replace those generations. In most countries the increased numbers of young people completing education and entering the labour market will not suffice to replace the large numbers of retirees. This implies that labour market shortages are likely to emerge.

\section{Active ageing as an approach to face the challenge}

The prolongation of working life is not only regarded as an important instrument to secure pensions in the future but also as a decisive answer to both the expected demographically induced labour shortages and the changing age composition of the workforce in many European Union (EU) countries. In many individual member states, early exit is being rethought. In the majority of older member states, like Austria, Belgium, Denmark, Finland, France, Germany, Italy, the Netherlands, the UK and Sweden, there have been pension reforms to curtail or to restrict access to early-exit schemes and programmes. The motivation for these changes was cost containment and financial balance in the face of an ageing population (see OECD, 2000). National policies are thus promoting raising the number of working years without necessarily implementing a systematic approach to cope with the consequences for the individuals involved. It is, however, evident that a prolongation of working life demands a restructuring of the entire individual work biography, e.g. reconciling work and private life through parental leave or care leave, and creating resources, such as educational leave, to maintain skills currency (human capital) (see for instance a special issue of this journal on retirement, Shultz and Henkens, 2010).

In this special issue we argue that active ageing can and should be defined not only in terms of activating pension policies with higher pension ages and lower benefit levels, which stimulate older adults to remain active in paid employment. According to a definition of the World Health Organisation, "active ageing is the process of optimising opportunities for health, participation and security in order to enhance quality of life as people age. It applies to both individuals and population groups. Active ageing allows people to realise their potential for physical, social, and mental well-being throughout the life course and to participate in society, while providing them with adequate protection, security and care when they need. The word 'active' refers to continuing participation in social, economic, cultural, spiritual and civic affairs, not just the ability to be physically active or to participate in the labour force. Older people who retire from work, ill or living with disabilities can remain active 
contributors to their families, peers, communities and nations. Active ageing aims to extend healthy life expectancy and quality of life for all people as they age". Following this definition we propose that scientific research on active ageing is in need of a more comprehensive approach acknowledging the important role of employers', civil society organisations' and governments' behaviour in promoting active ageing. This encompasses an increase in the labour force participation of older workers as well as the promotion of productive activities in the life phase of retirement such as the involvement of citizens in and commitment to matters of civil society. In this special issue we propose several directions for theoretical and methodological advancement, and present a number of contributions in which these approaches are developed. We will elaborate on these issues below.

First, we argue that active ageing applies not only to the paid labour market but also to the labour market of unpaid employment. The challenge for ageing societies goes beyond the paid labour market, and is also to increase older workers' participation in civil society. Civil society may also need these "younger" elderly as more women are participating in the labour market and have less time for care and volunteer work, while the share in the population of "older" elderly who need care is increasing. From another perspective, the growing share of seniors puts up the challenge to safeguard the social inclusion of all of these people, even though they may be low educated and worn out after a life of hard work. What do civil society organisations do to attract and activate seniors? These questions become more important as a growing number of persons in their 50s is confronted with the demographic phenomenon of being part of a four-generation family, with multiple tasks and care responsibilities, not only for grandchildren but also for elderly parents.

Second, research on active ageing needs a more comprehensive approach that acknowledges the role of different stakeholders, particularly at the demand side of the labour market. Even though policymakers at the government level may agree on and be convinced of the necessity to extend working lives, whether this macro-level goal can and will actually be achieved depends on individual workers' and especially employers' behaviour. Though there are examples showing that social partners reached agreements promoting the integration of older workers into the labour force, the points of view of trade unions and employers' organisations still differ widely on how and to what extent this should be attained. On the one hand, trade unions are concerned about high levels of unemployment and still favour early exit for certain groups of older workers, while at the same time they advocate improvements in working conditions to make prolongation of working life feasible (Hutsebaut, 2003). On the other hand, employers are demanding more flexible workforces and flexible working time schedules in order to reduce costs while also increasing competitiveness and extending service provision. Individual employers have used early-exit schemes as a strategic tool to reduce the size of workforces, though employers' associations are concerned about the costs of early exit. Studying employers' attitudes and behaviours is crucial to understanding the way ageing societies aim to extend the working lives.

Third, on the methodological side we will benefit from a broad methodological perspective in empirical research. The first has to do with the diversity across nations and cultures. Acknowledging this diversity in research on ageing societies may help us to understand the successes and failures of policy initiatives as well as the importance of cultural dimensions for the productive integration of older working and retired adults. The studies presented in this special issue build on empirical evidence from a wide selection of European countries. In addition, qualitative methods such as in-depth
Active ageing in Europe

607 
IJM

33,6

608 interviewing and case study research supplement quantitative studies that use largescale surveys and register data.

In that vein we thus present seven papers that address various aspects of active ageing. This special issue of the International Journal of Manpower focuses on the forces and mechanisms behind employers', civil society organisations' and governments' behaviour and the resulting societal arrangements. The different papers are developed within the framework of a large project funded by the EU called Activating Senior Potential in Ageing Europe (ASPA). In this project more than 20 researchers from eight different European countries shared their expertise to conduct cross-national research using multiple methods[2]. The project presents findings of survey research among employers $(N=6,000)$, case studies among employers and voluntary organisations, and policy analyses of comparative studies in eight European countries (Germany, UK, Denmark, Sweden, Italy, Poland, France and the Netherlands).

\section{Overview of this special issue}

In the first paper, Anxo, Ericson and Jolivet present some important features of the labour market for older workers in the different countries. They discuss policy implications of longer working lives in Europe, arguing that higher employment rates should not be reduced to merely an issue of safeguarding financial stability of pension systems. They point to several socio-economic consequences such as increasing inequalities between older workers, the need for sustainable working conditions, increasing risks of age discrimination and the impact of changing retirement ages on unpaid activities.

Next, the paper of Conen, van Dalen and Henkens is the first in this special issue to present results of the large-scale survey among employers carried out in the different countries. In this paper the authors examine employers' perceptions of how an ageing personnel structure affects organisational developments in labour costs and productivity, and whether such perceptions are related to their behaviour towards older workers. This paper also looks at how two factors which are assumed to hamper or stifle flexibility in the labour market - seniority wages and employment protection influence employers' perception of the gap between labour costs and productivity. The results show that a majority of European employers in each of the countries studied do not expect the ageing of their staff to affect their organisation's productivity level. With respect to employers' perception of consequences of ageing on labour costs the results show much more variation. Approximately half of European employers expect labour costs will increase as a result of an ageing staff. By combining perceptions on labour costs and productivity the authors show that about half of employers - although to different degrees per country - associate the ageing of their personnel with a growing gap between labour costs and productivity. Perceptions of high levels of employment protection and the use of seniority-based wage systems are associated with a larger cost-productivity gap. Moreover, perceptions of such a gap are not without consequences, as they negatively affect both recruitment and retention of older workers.

In the third paper, Conen, Henkens and Schippers follow up on employers' perception of the consequences on an ageing workforce, examining the different HRM policy instruments that are used and employers' views regarding the effectivity of public policy initiatives. The results of the survey show that although demotion and lifelong learning are suggested by scientists and policymakers as a way to bridge the gap between labour costs and productivity, the enthusiasm for actual implementation 
of these measures is not shared by employers. Employers have tended to implement flexible working hours as a measure aimed at accommodating older workers. Organisations in countries like the Netherlands and Denmark do take various measures to accommodate such needs, for instance by reducing older workers' workload or offering them possibilities for extra leave. The paper is among the first to address employers' views on governmental policies concerning older workers and extending working life. Interestingly, the most effective governmental measure to increase labour force participation of older workers - according to employers - are incentives that combine work and retirement.

The fourth paper, by Frerichs, Lindley, Alexandrowicz, Baldauf and Galloway, looks at good-practice examples that promote the employability, recruitment and retention of older workers. Their findings are based on 83 good-practice case studies among European employers. The study pays special attention to practices in areas that are rarely studied, particularly the public sector, as well as SME enterprises. The authors conclude that the case studies on age management in eight European countries do not reveal a general trend towards integrated age management. Single measures on training, lifelong learning and knowledge transfer are dominant. Measures aimed at health promotion, workplace design, career development and flexible working practices are also prominent in many cases. The authors point to the risks associated with the current economic crisis, resulting in increasing unemployment levels. The importance of age management seems to be downplayed when youth unemployment levels are on the increase.

In the final two papers we shift our attention to the unpaid labour market. The fifth paper, by Principi, Lindley, Perek-Bialas and Turek, addresses engagement in civil society from a demand-side perspective. As such, the paper offers insights on the topic of volunteering in old age from a previously largely neglected standpoint. The paper draws from 74 case studies of voluntary organisations in all eight ASPA countries, showing that countries differ substantially in their recognition of older volunteer potential. In some countries, like the Netherlands, Sweden and Denmark, organisations underline the positive qualities of older volunteers but at the same time think that too many older volunteers may be an obstacle to attracting younger ones. Countries like the UK, France and Germany have structured polices in place to retain and possibly increase the number of older volunteers. In Poland and Italy, which have an underdeveloped volunteer sector, age awareness is much lower and the focus lies on increasing voluntary participation of all ages. The sixth paper, by Pincipi, Chiatti and Lamura, focuses on the supply of unpaid employment in ageing societies, particularly on motivations of older adults to be active in volunteer work. Data are analysed from comparative surveys among older volunteers that have been collected in Italy, the Netherlands and Germany. In these surveys a volunteer function inventory was used to measure different motivations for volunteering. The paper shows that the most important motivation for older volunteers relates to values associated with altruistic beliefs, the least important to career-related benefits.

In sum, the collection of papers in this special issue provides a distinct international and interdisciplinary perspective on contemporary empirical findings on various issues related to active ageing. It is our hope that the findings reported here will also stimulate future research in the area of active ageing and paid and unpaid employment from both an individual- and an organisational-level perspective. We also hope that this special issue will contribute to the success of the European year for active ageing and solidarity between generations in 2012 .
Active ageing in Europe

609 
IJM

33,6

610

Finally, we would like to thank the reviewers who provided constructive suggestions and feedback for all authors. The set of six papers included in this special issue greatly benefited from the helpful advice of the ad hoc reviewers. We also thank the authors of the papers included here for their perseverance and professionalism in responding to the reviewers' suggestions and recommendations. Our gratitude extends to Professor Adrian Ziderman, the editor of $I J M$, for his support in approving and guidance in shepherding this special issue through the lengthy publication process.

\section{Notes}

1. Using the age of 50 to define "older workers" is arbitrary. However, as many studies and also most policymakers use the age of 50 to define older worker's labour market category, we adhere to this definition.

2. This research was funded by the EU Seventh Framework Programme (FP7/2007-2013) under grant FP7-216289 (ASPA). The editors gratefully acknowledge all consortium members: Per Jensen from Aalborg Universitet (Denmark); Annemarie Guillemard, Marielle PoussouPlesse and Denis Duplan from Ecole des Hautes Etudes en Sciences Sociales, CEMS/IMM (France); Frerich Frerichs and Paula Aleksandrowicz from the Research Centre for Ageing and Society (CAS) at the University of Vechta (Germany); Giovanni Lamura, Andrea Principi and Carlos Chiatti from the Department of Gerontological Research of the Italian National Research Centre on Ageing (INRCA) (Italy); Kène Henkens and Harry van Dalen from the Netherlands Interdisciplinary Demographic Institute, KNAW/NIDI (Netherlands); Joop Schippers and Wieteke Conen from Utrecht University (Netherlands); Jolanta Perek-Bialas and Konrad Turek from Jagiellonian University, Krakow (Poland); Dominique Anxo from the Centre for Labour Market Policy Research, Linnaeus University (Sweden); and Robert Lindley and Beate Baldauf from Warwick University (UK). See for more information: www.aspa-eu.com/

\section{References}

Ekamper, P. (1997), "Future age-conscious manpower planning in the Netherlands: from early retirement to a new perspective on the elderly?", International Journal of Manpower, Vol. 18 No. 3, pp. 232-47.

Eurostat (2005), "Population projections 2004-2050", available at: http://epp.eurostat. ec.europa.eu/portal/page/portal/eurostat/home (accessed 20 June 2012).

Hershey, D., Henkens, K. and van Dalen, H.P. (2010), "What drives retirement income worries in Europe? A multilevel analysis”, European Journal on Ageing, Vol. 7 No. 4, pp. 301-11.

Hutsebaut, M. (2003), "Active strategies for older workers: the point of view of the European trade union movement", Etudes et Dossiers No. 271, The Geneva Association, Work Beyond 60: Preparing for the Demographic Shock, pp. 183-90.

Klosse, S. and Schippers, J. (2008), "The integration of older workers in European labour markets: between macro desires and micro reality", in Pennings, F., Konijn, Y. and Veldman, A. (Eds), Social Responsibility in Labour Relations, Kluwer Law International, Alphen aan den Rijn, pp. 391-411.

van Nimwegen, N. and van der Erf, R. (Eds) (2010), "Demography monitor 2008; demographic trends, socio-economic impacts and policy implications in the European Union”, NIDI Report No. 82, monitoring report prepared by the European Observatory on the Social Situation - Demography Network, KNAW Press, Amsterdam, p. 166.

OECD (2000), Reforms in an Ageing Society, OECD, Paris.

Shultz, K.S. and Henkens, K. (Eds) (2010), "The changing nature of retirement", International Journal of Manpower, Vol. 31 No. 3, pp. 265-70. 


\section{About the Guest Editors}

Kène Henkens is a sociologist and Head of the Social Demography Department of the Netherlands Interdisciplinary Demographic Institute (NIDI). He is Professor of Sociology of Retirement at Tilburg University and is affiliated with Netspar. He has published extensively on issues regarding the labour supply in an ageing workforce. His main research interest lies in the area of an ageing workforce and retirement. Kène Henkens is the corresponding author and can be contacted at: henkens@nidi.nl

Joop Schippers is Professor of Labour Economics and the Economics of Equal Opportunity at Utrecht University. He has published a series of books and articles on male-female wage differences, human capital investments, labour market flexibility and organisational behaviour with respect to women and older workers.
Active ageing in Europe

611

To purchase reprints of this article please e-mail: reprints@emeraldinsight.com Or visit our web site for further details: www.emeraldinsight.com/reprints 